\section{AATS Member for a Day Award}

Accompany an AATS Member Mentor during portions of the AATS 100th Annual Meeting through the AATS Member for a Day Award. You will have the opportunity to gain insight into the cardiothoracic surgery specialty as well as network and build relationships within the cardiothoracic surgical community. You will also receive complimentary all-access registration to the scientific sessions at the Annual Meeting, as well as the AATS Member for a Day Session and the AATS/TSRA Resident Luncheon.

Apply to be one of the North American medical students, general surgery residents, up to third year integrated cardiothoracic surgery residents (I-6) and members of the American Physician Scientists Association (APSA) chosen to participate in the program.

\section{AATS Cardiothoracic Surgery Resident Poster Compe- tition}

Senior cardiothoracic surgery residents and/or congenital heart surgery fellows from around the world have the opportunity to present a scientific poster of their clinical/ investigative research at the 100thAnnual Meeting in
New York, NY. To represent your institution in the AATS Resident Poster Competition, provide a brief abstract (no more than 300 words) regarding the research. Posters may include research that has been previously presented and/or published.

\section{Perioperative/Team-Based Care Poster Competition}

Non-MD cardiothoracic surgical team professionals can participate in the AATS Perioperative/Team-Based Care Poster Competition at the AATS 100th Annual Meeting taking place in New York, NY. The posters should reflect the participant's research findings and/or new and innovative ideas for successful approaches in the management of the cardiothoracic patient. Abstracts previously presented at a national or international meeting may be submitted. The purpose of the competition is to present research findings and share new and innovative ideas for successful approaches in the management of the cardiothoracic patient. To be eligible for the program, cardiothoracic perioperative/team-based care professionals (NPs, PAs, Perfusionists, and RNs) must submit their abstract electronically through the submission site on the AATS Web site.

\section{The Western Thoracic Surgical Association}

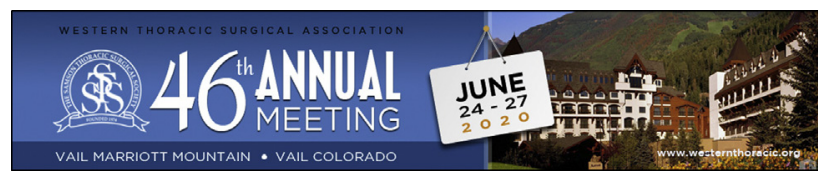

\section{WTSA 46th Annual Meeting}

\author{
Save the Date for the WTSA 46th Annual Meeting \\ June 24-27, 2020 \\ Vail Marriott Mountain \\ Vail, Colorado
}

\section{WTSA Traveling Fellowship for Residents, Trainees, and Practicing Surgeons}

Application Deadline: December 15, 2019.

The goal of this traveling fellowship is to promote interaction and learning between residents/trainees/ practicing surgeons and WTSA members. The traveling fellow will visit a University-affiliated or academic practice of his/her choosing, within the boundaries of the WTSA
(Alaska, Arizona, California, Colorado, Hawaii, Idaho, Montana, Nevada, New Mexico, Oregon, Utah, Washington, and Wyoming, along with Canadian provinces of Alberta, British Columbia, Manitoba, and Saskatchewan), for a period of one to two weeks, under the sponsorship of a Western member at the hosting institution. The traveling fellow does not need to be a WTSA member; the award is open to any resident/trainee/practicing surgeon. More details are available at westernthoracic.org.

\section{Applications for WTSA Membership}

Application Deadline: March 1, 2020.

The WTSA is now accepting Applications for Membership online for Active as well as Candidate membership status for the 2020 membership cycle. Visit the WTSA Web site at www.westernthoracic.org to read the complete membership eligibility requirements and to initiate an online application.

\section{Active Member}

$\$ 375.00$ annually, plus $\$ 50.00$ initiation fee

Applicant must meet all membership criteria, including but not limited to:

- Reside within or have completed a cardiothoracic residency training program within the geographic limits of the Association. 